\title{
O BLOG DE NOTÍCIAS: DO HIPERGÊNERO AO HIPERLEITOR
}

\author{
José Wanderley Souza Oliveira ${ }^{1}$
}

Vânia Lúcia Menezes Torga²

\begin{abstract}
RESUMO
À luz dos estudos bakhtinianos sobre a teoria da enunciação e dos gêneros do discurso, o presente trabalho tem como objetivo discutir as estratégias discursivas utilizadas por autor/leitor em blog de notícias, na internet. Com base nas concepções de Bakhtin, são abordadas as estratégias discursivas presentes no blog Pimenta na Muqueca, considerando-se a ocorrência da mediação desse hipergênero e a constituição do leitor. Foram selecionadas, aleatoriamente, três notícias contendo comentários de leitores, as quais foram extraídas do blog, que se encontra hospedado na internet no endereço: www.pimenta.blog.br. Levando-se em conta as questões de uso da língua através da tecnologia e da linguagem mediada por computador, a opção pelo blog justifica-se por se tratar de uma ferramenta criada para permitir a interação com o usuário, ou seja, é um espaço virtual onde o leitor pode responder, comentar e, com isso, redimensionar os textos veiculados. Portanto, neste estudo, são observadas as estratégias utilizadas por leitores do blog Pimenta na Muqueca, os quais, através de seus comentários, num movimento simultâneo de concordar e/ou discordar, assumem uma atitude responsiva ativa e complementam o discurso, tornando-se também autores dos textos veiculados.
\end{abstract}

Palavras-chave: Gênero. Discurso. Autor. Leitor.

\section{INTRODUÇÃO}

A partir do surgimento do computador e, mais tarde, com a criação da internet, passou a ser possível o estabelecimento da comunicação entre as máquinas e entre os seus usuários. Assim, foi criada a rede mundial de computadores, uma revolução tecnológica considerada um repositório acessível de 
quase todo o conhecimento existente, a qual vem influenciando, sobremaneira, as práticas de leitura e escrita. Com isto, o uso de tecnologias como o lápis, a caneta, o giz, o quadro negro, o caderno, o livro impresso, etc., vem sendo substituído por inserção de dados via teclado, cliques através de mouse, ou ainda, por um leve toque na tela, conhecido como touch screen, para que os comandos sejam dados e as operações sejam realizadas nos modernos equipamentos disponíveis.

Desta forma, o computador, seja no modelo desktop ou laptop, o palm top, os avançados aparelhos de telefone celular e o recém-chegado tablet, todos com acesso à internet, vêm se popularizando e se inserindo no cotidiano das pessoas de tal forma que o seu uso tornou-se quase indispensável, propiciando maior agilidade na comunicação em massa e a excelência na realização dos diversos tipos de atividades do dia a dia, seja para assuntos domésticos, escolares, profissionais ou ainda para simples lazer.

A constante modernização da capacidade de conexão em rede e de difusão da informação tem aumentado a interação entre os usuários da tecnologia em epígrafe, fazendo do ato de ler e escrever através do computador uma prática constante, seja digitando texto, enviando e/ou respondendo email, lendo notícias em blogs, navegando na internet, conversando em fóruns, chats ou em salas de batepapo; todo o uso se dá através da antiga tecnologia ou habilidade de leitura e escrita. Com isso, conhecidas teorias dedicadas ao campo da linguagem, como as que versam sobre tipologias textuais e dialogismo, a exemplo das contribuições de Mikhail Bakhtin (1997), vêm embasando estudos que surgem a partir das novas formas de se praticar leitura e escrita, e ampliando a noção de letramento.

Nessa linha, sobre o sentido de letramento, Soares (1998) defende que muito mais do que decodificar o sistema alfabético, é necessário se apropriar dos usos sociais da escrita. Por conseguinte, essa concepção se estende ao conceito de letramento digital que implica colocar os sujeitos em contato com a linguagem das modernas tecnologias digitais, de forma a utilizá-las e aplicá-las na sua vida cotidiana. Assim, Soares (1998) afirma que o indivíduo considerado alfabetizado é aquele que sabe ler e escrever; mas aquele que vive em estado de letramento, não só sabe ler e escrever, como também usa essas tecnologias socialmente. Daí depreende-se que o sujeito letrado digital é aquele que incorpora e aplica os sistemas alfabético e tecnológico nas suas práticas sociais. Tal ideia é enfatizada por Kleiman (1995, p. 8), ao afirmar que "o domínio de outros usos e funções da 
escrita significa, efetivamente, o acesso a outros mundos, públicos e institucionais, como o da mídia, da burocracia, da tecnologia".

Percebe-se, assim, que, com as transformações a que a sociedade vem sendo submetida, com o avanço tecnológico, muitas teorias podem ser úteis, acompanhando a evolução científica. Nessa visão, insere-se Mikhail Bakhtin e sua abordagem sobre a enunciação e os gêneros do discurso, a qual respalda esta pesquisa, que tem como objetivo discutir as estratégias discursivas utilizadas por autor/leitor de blog de notícias, veiculadas na internet. Partindo-se das concepções bakhtinianas, são abordadas as estratégias discursivas presentes no blog Pimenta na Muqueca, considerando-se a ocorrência da mediação desse hipergênero e a constituição do hiperleitor.

A opção pelo blog decorreu de se tratar de ferramenta de amplo acesso na internet e por permitir que haja interação entre escritor e leitor. Este, conforme Bakhtin (1997), através de seus comentários, sempre faz frente ao enunciado, dando-Ihe resposta, seja concordando, complementando ou discordando do ponto de vista abordado no blog. De acordo com Bakhtin (1997), é nesse movimento de troca discursiva que se estabelece a atitude responsiva ativa do leitor, o qual passa a ser também autor do texto, complementando-o e redimensionando-o com a sua opinião.

Salienta-se que este artigo está composto das seguintes partes: 1 Introdução 2 Os gêneros do discurso em Bakhtin; 3 Tecnologia e linguagem; 3.1 A constituição do leitor de hipertextos; 3.1.1 O blog Pimenta na Muqueca; 4 Considerações finais; e referências.

\section{OS GÊNEROS DO DISCURSO EM BAKHTIN}

A linguística geral, incluindo-se a saussureana, do ponto de vista da comunicação verbal, apresenta uma visão dual dos sujeitos do discurso, ao considerar locutor e ouvinte como duas faces, em que, por um lado, o termo ouvinte alude a uma ideia de inércia e atribui certa passividade ao sujeito, que parece ter pouca atuação no diálogo, já que é um receptor do discurso e, por outro lado, tem-se o locutor, a quem é atribuída a tarefa de oferecer o discurso, conforme Bakhtin (1997). 
Com os estudos sobre os gêneros do discurso em Estética da criação verbal, Bakhtin (1997), apresenta seu olhar sobre a comunicação verbal, considerando o enunciado ou a enunciação como ponto de partida, e os sujeitos envolvidos, locutor e ouvinte, ambos com papéis ativos na construção do sentido do discurso. Para o autor, é no instante da enunciação que a discursividade é colocada em prática e acontecem, entre os partícipes, os movimentos estratégicos de interação, os quais são também influenciados pelos ecos de outros enunciados com os quais têm relação, dando vida ao discurso. Nesse sentido, ao contrário da dualidade, o autor concebe um caráter de unicidade discursiva, como uma simbiose entre locutor e ouvinte, na qual, através da atitude responsiva ativa, o ouvinte também se torna locutor e, juntos, proferem e recriam o discurso, pois para Bakhtin (1997, p. 291) "cada enunciado é um elo da cadeia muito complexa de outros enunciados".

Todavia, é preciso esclarecer que a unicidade discursiva em questão representa uma união, mas nem sempre aceitação ou adesão, pois esta se dá pela participação do ouvinte no discurso, aderindo a ele ou não, através de uma postura em que ele se prepara para a réplica, também influenciado por outros discursos. Nesses termos, a tensão não é descartada, tendo em vista que

\begin{abstract}
o ouvinte que recebe e compreende a significação (linguística) de um discurso adota simultaneamente, para com este discurso, uma atitude responsiva ativa: ele concorda ou discorda (total ou parcialmente), completa, adapta, apronta-se para executar, etc., e esta atitude do ouvinte está em elaboração constante durante todo o processo de audição e de compreensão desde o início do discurso, às vezes já nas primeiras palavras emitidas pelo locutor. (BAKHTIN, 1997, p. 290).
\end{abstract}

Assim, a necessidade de introduzir o enunciado deve-se ao seu importante papel nos variados modos de utilização da língua na atividade humana, falada ou escrita, e pelo seu desdobramento em gêneros do discurso. Segundo Bakhtin (1997, p. 279) "conteúdo temático, estilo e construção composicional fundem-se indissoluvelmente no todo do enunciado e todos eles são marcados pela especificidade de uma esfera de comunicação". Isto dá uma ideia de certa estabilidade às variadas formas de uso da língua, seja oral ou escrita, pois são conservadas certas unidades enunciativas demandadas das atividades $e$ necessidades humanas. Essa relativa estabilidade denomina-se gênero do discurso.

Para Bakhtin (1997), assim como os enunciados, os gêneros do discurso tornam-se heterogêneos na medida em que são usados, seja para produzir os 
diálogos do dia a dia, seja para reproduzir o romance, a literatura, inclusive leis e outros documentos oficiais. Para ele, em virtude da dificuldade de se definir o caráter genérico do enunciado, o que importa é considerar a diferença entre os gêneros do discurso, que são divididos entre primários e secundários, também conhecidos, respectivamente, como simples e complexos.

O autor afirma que os gêneros complexos são "o romance, o teatro, o discurso científico, o ideológico, etc." (BAKHTIN, 1997, p. 281). Já os gêneros simples constituem a comunicação verbal espontânea, a fala do cotidiano, a escrita despreocupada. O autor completa, dizendo que os gêneros complexos são relativamente superiores e mais evoluídos do que os gêneros simples, em virtude de os complexos absorverem os simples no momento da sua criação, ou seja, os gêneros simples integram a criação do gênero complexo, no momento em que eles adquirem a forma escrita culta.

A teoria bakhtiniana volta-se para o estudo da linguagem a partir dos contextos histórico, político, econômico e social, na perspectiva da atividade humana coletiva, constituída pela interação verbal e concretizada através da enunciação. $O$ que, no momento atual, inclui as atividades de leitura e escrita que estão sendo realizadas de várias formas, seja com a finalidade de estudo, trabalho ou lazer, através do computador e das modernas mídias que compõem as novas tecnologias da informação e comunicação e funcionam como suporte, dentre as quais o blog está inserido, caracterizado como um hipergênero capaz de propiciar a interação enunciativa entre leitor e escritor de textos de notícia, através de feedback produzido por réplicas e tréplicas nos comentários virtuais.

\section{TECNOLOGIA E LINGUAGEM}

De acordo com Stallings (2002), o primeiro computador de que se tem notícia, o ENIAC (Computador e Integrador Numérico Eletrônico), foi criado por cientistas americanos durante a segunda guerra mundial, para a realização de cálculos, no Laboratório de Pesquisas Balísticas, órgão responsável por desenvolver tabelas de trajetória e alcance para novas armas bélicas, o que exigia conhecimento substancial de matemática. Assim, apesar do ENIAC só se ter tornado operacional após a guerra, sua criação representou o passo inicial para a evolução da tecnologia computacional. 
A partir daí, foram sendo descobertas as inúmeras possibilidades de uso do computador, com seus programas, passando das funções de realização de cálculo, do ENIAC, para a construção de textos, tabelas, arquivos de som e imagem, dentre outros, além da possibilidade de difundir os dados gerados e transformá-los em informação. Não demorou muito para que o uso de programas de computador se tornasse tecnologia avançada $\mathrm{e}$, com $\mathrm{o}$ surgimento da rede mundial de computadores, através da internet, passar a se constituir num importante suporte para o campo da linguagem, permitindo o contato verbal, falado e escrito, em tempo real, entre pessoas de qualquer parte do mundo.

De acordo com Paiva (2011), a partir do computador, outras tecnologias foram surgindo até se chegar às Novas Tecnologias da Informação e Comunicação - NTIC, que estão revolucionando o contexto informacional e comunicativo com as mais novas mídias e os novos software's (programas) disponibilizados em rede, através da internet, que avançam cada vez mais para satisfazer as necessidades humanas.

Nesse contexto, a internet e todas as inovações surgidas até o presente momento, transmitidas através de aparelhos como desktop, laptop, palmtop, smartfone, tablet, etc., formam o contexto digital que está posto no cotidiano dos sujeitos de todos os níveis sociais e vem transformando não só os suportes através dos quais se pode realizar leitura e escrita, como as formas de se elaborar estas tarefas.

Para Marcuschi e Xavier (apud ARAÚJO, 2007, p. 15) "o computador está presente em quase todas as áreas do cotidiano das pessoas, como nas corriqueiras operações bancárias que fazemos em caixas eletrônicos espalhados pelos quatro cantos do país". Com isto, a intercomunicação que vem acontecendo de forma on line, tem disponibilizado uma grande variedade textual, fruto da interação virtual que atinge a massa de escritores e leitores usuários das tecnologias, influenciando os processos de linguagem.

Com a constante ampliação do acesso, da capacidade e da velocidade na transmissão de dados via internet, de forma quase instantânea, réplicas e tréplicas compõem um modo de enunciação nas trocas discursivas digitais que podem ser visualizadas, acompanhadas ou seguidas nas redes sociais, nas páginas pessoais, nos blogs de notícia, dentre outros. O avanço tecnológico permite que as informações sejam acessadas, passando-se de um texto a outro através de cliques 
em fragmentos do próprio texto, que aparecem em forma de links, e transportam a leitura tanto a outros textos, como também para arquivos de imagem e som.

Desta forma, o texto passa a ser um hipertexto e alguns gêneros discursivos são concebidos como hipergêneros, pois aproximam virtualmente autores e leitores, permitindo-Ihes a interatividade dialógica através de uma grande variedade de textos. Snyder (apud ARAÚJO e BIASE-RODRIGUES, 2005, p. 51) define hipertexto como "uma estrutura composta por blocos de textos conectados por links eletrônicos, os quais oferecem diferentes caminhos para os usuários". Nesse sentido, o blog ilustra a concepção de hipergênero por hospedar diferentes blocos de textos que se traduzem em diferentes tipos textuais e que, ao mesmo tempo, fazem do blog um suporte de hipertextos.

Através desse canal as distâncias entre autor e leitor se encurtam ainda mais. O avanço tecnológico torna possível conversar diretamente com o autor, tirar dúvidas, fazer-lhe perguntas e receber respostas ou simplesmente registrar comentário, emitindo opinião, concordando, discordando ou completando informação. Seja como for, ainda que por meio virtual, percebe-se o estabelecimento da troca discursiva e da interação verbal.

Essa interação escritor/leitor, na internet, é bastante recorrente em blogs, sobretudo nos blogs de notícia, nos quais há a participação do leitor através de espaço específico para isso. É lá que se obtém, muitas vezes, o registro de respostas sem compromisso ou apenas algumas observações desdenhosas, mas também é onde se encontram respostas e/ou comentários comprometidos com a veracidade das informações e da formação de opinião acerca da notícia veiculada. Nesse espaço virtual pode-se observar a intencionalidade de dialogar com o autor e com os outros possíveis leitores.

Bakhtin (1997) comenta que esse comportamento em que os enunciados do leitor e do autor se fundem em interação, traduz a expectativa do locutor, pois este não "espera uma compreensão passiva que, por assim dizer, apenas duplicaria seu pensamento no espírito do outro, o que ele espera é uma resposta, uma concordância, uma adesão, uma objeção, uma execução, etc." (BAKHTIN, 1997, p. 291). Desta forma, réplicas e tréplicas complementam o texto inicial e, por vezes, ampliam o seu sentido e a sua carga informacional, como se passasse a ser um texto cunhado por vários autores, considerando-se que eles tenham assumido perante o diálogo a atitude que para Bakthin (1997), de acordo com a citação 
anterior, se traduz em respondibilidade, que é a capacidade de resposta, seja qual for, desde que feita de forma responsável.

Assim, num blog de notícia, dada a variedade de gêneros discursivos, com notícias publicadas quase que instantaneamente, no decorrer das horas do dia, à luz das concepções bakhtinianas, é possível perceber as estratégias discursivas mobilizadas por autores e leitores que, juntos, em interação com o enunciado, redimensionam e complementam o discurso.

\subsection{A Constituição do Leitor de Hipertextos}

Nas discussões sobre leitura de hipertextos, que é uma leitura virtual, entra em jogo a compreensão de aspectos, tais como: a influência exercida pelos instrumentos ou suportes que permitem a realização de leitura; a postura do leitor perante a variedade textual; e o perfil que ele possui. É, pois, através da observação de tais condições, consideradas a seguir, que serão feitas inferências sobre leitura na internet, especificamente em blog de notícias, por se tratar de um hipergênero que reúne blocos de tipos textuais variados, que caracterizam os hipertextos.

De acordo com Arena (2007, p. 30) é preciso lançar mão de estratégias apropriadas para o tipo de leitura realizada na tela do computador. Conforme a autora cita, esse tipo de leitura "é mediada por três variáveis, o sujeito; o texto, suporte socialmente elaborado que aponta para a terceira delas, as experiências e os conhecimentos acumulados historicamente para a constituição dos objetos" (ARENA, 2007, p. 30). Contudo, não basta saber operar os equipamentos ou utilizar a tecnologia, é preciso saber interagir com a informação e com os informantes do mundo digital.

Daí percebe-se que os aspectos a serem observados, citados no início desta sessão, por se constituírem em ações, atitudes e efeitos com finalidades e resultados interligados, podem ser considerados como uma influência da tecnologia e do campo digital, desencadeando um comportamento leitor que exige, dentre outras coisas, atitude responsiva e disciplina, ou seja, a adoção de atitude responsável para com a interlocução em jogo de forma a selecionar a leitura ou as leituras que realmente lhe importam e lhe interessam.

Para um leitor maduro, que tem como foco a busca de significado e a construção de sentido, isto não representa tanto problema, porém, para outros, 
como aqueles em fase de aprendizagem, o hipertexto pode se transformar numa busca sem fim e, talvez, sem resposta, haja vista a infinidade de outros textos que surgem cada vez que um novo link é clicado. É diferente do suporte impresso, no qual é possível saber onde a leitura vai chegar, pela certeza de que o texto possui, visivelmente, um "final". Todavia, é comum encontrar leitores que para escolherem ou se interessarem por um livro, por exemplo, baseiam-se na espessura e quantidade de páginas, pois este suporte não lhes permite prever se a leitura será interessante por inteiro.

No meio digital, embora haja opção de o leitor direcionar a leitura para aquilo que realmente lhe interessa, conforme Pinheiro (2005, p. 145) nem sempre o foco é tão preciso, pois "apesar de os hiperleitores selecionarem alguns links para ler, o tamanho do fragmento e o tempo disponível para sua leitura definirão se o texto realmente será lido". Por outro lado, diferentemente do suporte impresso em que as páginas são passadas sequencialmente, seguindo a ordem, para que a compreensão se estabeleça, o hipertexto possibilita uma leitura não linear, que pode ser iniciada a partir do texto que surgir na tela do computador, de vez que este se encontra indexado no site ou blog onde está sendo realizada a leitura, basta que o usuário leitor navegue, mesmo de trás para frente, dando cliques, avançando e/ou voltando nos textos, e a leitura estará acontecendo.

As considerações aqui realizadas conduzem à acepção de que o ato de navegar na internet é, eminentemente, um ato de busca através de leitura. Todavia, no que concerne ao leitor de hipertextos e do emaranhado de caminhos a serem seguidos há a possibilidade de leitura assíncrona, em virtude da disposição em blocos da massa textual que está ligada por hiperlinks e, de acordo com Pinheiro (2005), da coerência que o hiperleitor precisa estabelecer com os hiperlinks e os autores aos quais a sua leitura, por vezes, estará relacionada.

\subsubsection{O blog Pimenta na Muqueca}

O blog denominado Pimenta na Muqueca pode ser acessado através do endereço: www.pimenta.blog.br. Como blog é um tipo de site, o Pimenta na Muqueca foi desenvolvido e é hospedado pela webtivaHOSTING, uma empresa que cria e hospeda sites no seu servidor, e localiza-se na internet no endereço: www.webtiva.com.br. 
O Pimenta na Muqueca veicula, diariamente, notícias locais, regionais e algumas nacionais, de grande repercussão, que são classificadas por categorias, tais como: cultura, esporte e geral. Além disso, há espaço para publicação de artigos e entrevistas, e a disponibilização, em cada publicação, de local específico onde os leitores podem emitir opinião, concordando ou discordando; fazer questionamentos; acrescentar informações, etc., ou seja, é um link em que o leitor pode participar do texto, interagindo com o próprio blog e com os autores das publicações.

Nessa linha, esta pesquisa aborda questões de uso da língua através da tecnologia e da linguagem mediada por computador, sob a ótica dos estudos bakhtinianos, que versam sobre a teoria da enunciação e dos gêneros do discurso. Por isso, o trabalho teve como objetivo tratar das estratégias discursivas utilizadas por autor/leitor de hipertexto em blog de notícias, na internet, observando-se a atitude responsiva ativa do leitor, o que o torna também autor do texto, no momento da enunciação e da troca discursiva (BAKHTIN, 1997).

Para se delinear o comportamento de autor e leitor, parte-se da análise de três notícias divulgadas pelo blog Pimenta na Muqueca, na categoria geral, em maio de 2012, as quais constam em anexo. As publicações são as seguintes: 1) Risco na Rodovia Ilhéus-Itabuna (http://www.pimenta.blog.br/2012/05/16/risco-na-rodoviailheus-itabuna/\#comments); 2) Prefeituras Baianas Descumprem Lei de Acesso à Informação(http://www.pimenta.blog.br/2012/05/16/prefeituras-baianas-descumpremlei-de-acesso-a-informacao/\#comments); 3) O Golpe (Frustrado) de Coronel Santana (http://www.pimenta.blog.br/2012/05/16/o-golpe-frustrado-de-coronel-santana/.

$\mathrm{Na}$ análise, os nomes dos leitores aparecerão, tal qual publicado pelo blog. A primeira notícia atribui ao DERBA, órgão responsável pela manutenção de estradas, a falta de conservação do asfalto da rodovia Ilhéus-Itabuna, na Bahia, colocando em perigo quem nela trafega, dando ênfase ao mato que cresce às margens e às barracas para venda de frutas e pescado que são instaladas no acostamento, próximo ao quebra-molas. Os comentários postados pelos leitores demonstram interesse no assunto. Eles fazem reclamações ao poder público e adicionam informações que complementam a notícia, evidenciando o conhecimento das condições da rodovia e o descontentamento com tal situação.

A leitora Maria Ferreira vai além da crítica ao DERBA, ao afirmar que a estrada é federal, mas a responsabilidade de preservá-la é do governo estadual, que recebe verba "de Brasília", ou seja, do governo federal. Além 
disso, ela indica trecho específico da pista onde os buracos podem causar acidente grave, com risco de algum veículo cair no rio. Chama a atenção o estilo irônico para criticar o governo do estado, utilizado pelo leitor Zumbi, que diz: "Está parecendo um ramal!! É o governo da Bahia fazendo mais, para quem mais precisa" e completa " tudo uma dia vai mudar... tenho fé. Mas uma coisa é certa, está esperando acabar para privatizar".

Observa-se que o leitor lança mão da ironia como recurso estilístico para dizer exatamente o contrário, que o governo não está fazendo por quem mais precisa e, sim, que está deixando de cuidar da estrada para reforçar o argumento da privatização, medida adotada por outros governos, no Brasil, com empresas públicas e estradas, muitas vezes sob fortes críticas, rumores de fraude, de beneficiamento ilícito e de contratos obscuros. Vê-se que, junto com tal resposta, emergem ecos de outros discursos, que interferem no comportamento discursivo deste ouvinte leitor e influenciam a sua capacidade de interação e de responsabilidade para com a resposta. A partir da réplica em análise, percebe-se que o leitor vai de encontro ao enunciado da notícia, mostrando outros possíveis desdobramentos, o que redimensiona o texto inicial e prepara o terreno para a continuidade do jogo enunciativo.

A notícia número 2, Prefeituras Baianas Descumprem Lei de Acesso à Informação, trata do descumprimento, por parte de prefeituras municipais da capital e interior, da lei de acesso à informação, sancionada pela Presidenta Dilma Roussef, neste ano. A lei garante aos cidadãos acesso, através da internet, às ações governamentais nos três poderes e nos níveis de governo federal, estadual e municipal, tais como: licitações, contratos, execuções orçamentárias e destinação de verbas. Em resposta ao fato de algumas prefeituras baianas não estarem cumprindo o dispositivo, a notícia recebeu a manifestação de seis leitores, todos, cada um ao seu estilo, defendendo a transparência das contas públicas e o direito do cidadão ter acesso a esse tipo de informação.

Contudo, o leitor Sérgio Oliveira, o primeiro a comentar, inicia citando outro caso, mas com o mesmo viés, em que a imprensa está tendo acesso negado aos registros de um hospital local. Fazendo uma comparação, ele utiliza esse assunto para abordar a notícia postada pelo blog e, assim como nos comentários dos outros leitores, deixa pistas confirmando a arena onde pode ser observada a responsividade. Na sua postagem, o referido leitor inverte a ordem das informações do seu discurso, ao escrever: 
Pelo jeito, o pessoal do... (cita o partido político, que é o mesmo do executivo estadual baiano e federal) gosta de uma nostalgia similar ao que ocorreu na época da didatura. Deve ser para dificultar a divulgação das ocorrências e o povo pensar que está tudo bem.

e finaliza com outra inversão, em tom de ironia, só que agora com o jingle do mesmo governo estadual, que diz: "Pois agora tem, tem, tem, ... DITADURA, ... CENSURA, ... FALTA DE LIBERDADE DE EXPRESSÃO", o que dá a ideia de que essa é a postura do governo da Bahia.

Acontece que o partido citado é o mesmo que, no passado, lutou contra a didatura, a opressão e a censura, e a favor da liberdade de expressão do cidadão e da imprensa. Quando ele cita "ao pessoal desse partido", remonta, de certa forma, aos militantes do partido que por mais de uma década fez oposição aos governos da ditadura militar, no Brasil, muitos defendendo seus ideais com a própria vida. Ocorre que, hoje, remanescentes dessa militância política são ocupantes de cargos políticos de grande expressão no país e de altos escalões em todas as esferas de governo. Por isso, o leitor Sérgio Oliveira, faz uma denúncia, declarando que, agora que é esse mesmo pessoal que está no poder, eles dificultam a divulgação "das ocorrências" e mantêm a verdade distorcida, fazendo "o povo pensar que está tudo bem".

Nessa linha, observa-se a influência de outros discursos no enunciado deste leitor, o qual, com sua atitude responsiva ativa, permite que outros leitores e o próprio autor da notícia façam novas inferências e recriem o texto que originou esta discussão. Como exemplo, pode ser agregado à enunciação que ora se discute, o pensamento de Paulo Freire acerca das manobras discursivas do poder a que a sociedade está submetida, em que o autor afirma que

a própria miopia que nos acomete dificulta a percepção mais clara, mais nítida da sombra. Mais séria ainda é a possibilidade que temos de docilmente aceitar que o que vemos e ouvimos é o que na verdade é, e não a verdade distorcida. (FREIRE, 1996, p. 142).

Desta forma, é possível perceber que o leitor que compõe esta análise está dialogando com o enunciado iniciado pelo autor da notícia e expandindo-o através da sua réplica. Com esta atitude, de acordo com as considerações de Bakhtin (1997), ele reelabora o texto e passa a integrar a sua autoria.

A terceira notícia selecionada, O Golpe (Frustrado) de Coronel Santana, trata da confusão ocorrida numa reunião da Assembleia Legislativa da Bahia, em que o 
deputado estadual Coronel Gilberto Santana tentou inserir na pauta, sem o conhecimento do poder público ilheense, o projeto que versa sobre os limites de território entre os municípios de Itabuna e llhéus. Segundo o informe, a intenção do Coronel seria diminuir o limite de llhéus, consequentemente, ampliando o de Itabuna, o que absorveria algumas empresas de grande porte que estão instaladas próximo às áreas limítrofes, mas do lado de llhéus. Porém, os políticos de llhéus se uniram e conseguiram manter as medidas originais do projeto.

O leitor intitulado Grapiúna dispara seu apoio à atitude do Coronel e solicita ao prefeito de Itabuna que suspenda serviços prestados, a exemplo da coleta de lixo, às empresas que se localizam na entrada da cidade, mas que pertencem a Ilhéus. Para saber se tal coleta realmente é feita por Itabuna, consultou-se a empresa responsável pelo serviço no município, que informou não atender na área citada, confirmando que esse e outros serviços públicos são realizados pela prefeitura de llhéus.

Neste caso, pode ser avaliada mais de uma possibilidade de perspectiva do leitor. Tanto pode ser um equívoco, como pode ser sua intenção polemizar para que a verdade venha à tona. Importa saber que ele é responsável pelo que afirma, tanto quanto somos todos responsáveis pelo que dizemos, inclusive, sob o risco de ter que responder juridicamente por atitudes verbais.

Considerando a primeira possibilidade, do leitor está realmente apresentando uma informação enganosa, isto caracteriza a ausência de resposta pautada na responsabilidade e na ética, por confundir outros leitores menos avisados e propagar, equivocadamente, a informação, o que não corresponde ao que Bakhtin (1997) atribui à atitude responsiva ativa. Para ele, esta se estabelece no nível da interação, através de uma atitude ética, atenciosa e respeitosa do interlocutor para com os enunciados que compõem a troca discursiva.

Por outro lado, a atitude polemizadora do discurso através de um equívoco aparente, pode, na verdade, ser um equívoco proativo, intencional, que conduzirá a réplica à seara da respondibilidade, por incitar a enunciação a ir ao encontro da verdade, a partir dos pontos de vista que permearão a discussão e darão ao texto inicial continuidade e fluidez, desde que estejam em consonância com as intenções enunciativas em jogo. 


\section{CONSIDERAÇÕES FINAIS}

De acordo com os estudos bakhtinianos, sobre a teoria da enunciação e os gêneros discursivos, o momento da enunciação que corresponde à troca discursiva, seja entre falante e ouvinte ou entre autor e leitor, em dado discurso, forma a arena onde se estabelece a responsividade, o que Bakhtin (1997) chama de atitude responsiva ativa por parte do interlocutor que interage com o discurso e entra no jogo.

Por isso, as considerações apresentadas neste trabalho conduzem à reflexão sobre estratégias discursivas de autor e leitor, que emergem através da internet, no hipergênero blog de notícias, em função da sua característica de reunir tipos textuais variados e, ao mesmo tempo, ser um suporte de hipertextos. Esse tipo de conjugação textual virtual exige do leitor um papel ativo na construção de sentido dos discursos, por sua responsabilidade para com os enunciados postados em forma de comentários que compõem suas réplicas e tréplicas e repercutem no escopo informativo do texto inicial.

A mediação nesse hipergênero e a constituição do leitor dizem respeito tanto ao binômio tecnologia/linguagem, como à constituição do leitor de hipertextos, que de sua parte exige postura, cuidados especiais com o que afirma e disciplina frente à variedade textual com que se depara. Sua adesão ao diálogo proposto garante o prosseguimento discursivo da leitura e da escrita, transformando e ampliando o discurso inicial. Ressalta-se que, na visão bakhtiniana, a atitude responsiva representa coautoria do texto e exige veracidade e responsabilidade por parte de quem decide participar ativamente do debate.

Para mostrar como isso ocorre, foram analisadas três notícias, sobre assuntos diversos, publicadas pelo blog de notícia Pimenta na Muqueca, bem como os comentários de alguns leitores, considerando-se esta relação como a arena onde se constitui o grau de responsividade que justifica uma análise.

Os resultados permitiram entender e discutir a importância da atitude assumida pelo leitor no momento em que este, através da réplica, interage com a notícia e a redimensiona, permitindo que outros leitores e até mesmo o próprio autor, com sua tréplica, também aja de acordo com a veiculação da verdade que aquele texto, por ventura, tem por objetivo divulgar, respeitando a interação entre os enunciados e visando à formação de opinião. 


\title{
NOTAS
}

\footnotetext{
${ }^{1}$ Mestre em Letras: Linguagens e Representações, na Universidade Estadual de Santa Cruz - UESC. Analista Universitário lotado na Pró-Reitoria de Extensão da UESC. Professor da rede estadual de ensino, ministrando aula para o Ensino Médio e EJA. E-mail: wanderleyso@hotmail.com.

2 Doutora em Linguística pela Universidade Federal de Minas Gerais. Professora Adjunta da Universidade Estadual de Santa Cruz - UESC, ministrando aula na Graduação e no Mestrado em Letras: Linguagens e Representações. Tem experiência na área de Letras, atuando, principalmente, nos seguintes temas: leitura/escrita, alusão, gêneros discursivos, texto literário e de divulgação científica e cultural. E-mail: vltorga@uol.com.br.
}

\section{THE NEWS BLOG: FROM HIPERGENRE TO HIPER READER}

\begin{abstract}
From the Bakhtin studies about theory of utterance and speech genres this paper aims to discuss the discursive strategies used by author / reader blog of news, on the internet. Based on the ideas of Bakhtin, addresses the discursive strategies present in the blog Pimenta na Muqueca, considering the occurrence of mediate that hypergenre and the constitution of the reader. Were randomly selected three news containing comments from readers, which were taken from the blog, which is located on the internet under: www.pimenta.blog.br. Considering the issues of language use through language technology and computer mediated the option for the blog is justified because it is a tool designed to allow interaction with the user, in other words is a virtual space where the reader can answer, comment and with it resize the texts. Therefore, in this study are observed the strategies used by readers of the blog Pimenta na Muqueca which through their comments in a simultaneous movement to agree and / or disagree assume an active responsive attitude and complement the speech, also becoming authors of texts running.
\end{abstract}

Keywords: Genre. Speech. Author. Reader. 


\section{REFERÊNCIAS}

ARENA, Adriana Pastorello Buim. A internet como instrumento e seu papel na formação do leitor. In: ANDRÉ, Marli Eliza E. D. A. (Org.). Etnografia da prática escolar. 13. ed. Campinas: Papirus, 2007.

ARAÚJO, Júlio César. (Org). Internet e ensino: novos gêneros, outros desafios. Rio de Janeiro: Lucerna, 2007.

ARAÚJO, J. C.; BIASI-RODRIGUES, Bernadete (Orgs.). Interação na Internet: novas formas de usar a linguagem. Rio de Janeiro: Lucerna, 2005.

BAKHTIN, Mikhail. Os gêneros do discurso. In: Estética da criação verbal. Trad. Maria Ermantina Galvão G. Pereira. 2. ed. São Paulo: Martins Fontes, 1997.

FREIRE, Paulo. Pedagogia da autonomia: saberes necessários à prática educativa. São Paulo: Paz e Terra, 1996.

KLEIMAN, Ângela B. (Org.). Os significados do letramento: uma nova perspectiva sobre a prática social da escrita. Campinas: Mercado das Letras, 1995.

PAIVA, Vera Lúcia Menezes de O. O uso da tecnologia no ensino de línguas estrangeiras: breve retrospectiva histórica. 2011 (no prelo). Disponível em: <http://www.veramenezes.com/publicacoes.html>. Acesso em: 27 jun. 2012.

PINHEIRO, Regina Cláudia. Estratégias de leitura para a compreensão de hipertextos. In: ARAÚJO, J. C.; BIASI-RODRIGUES, Bernadete (Orgs.). Interação na Internet: novas formas de usar a linguagem. Rio de Janeiro: Lucerna, 2005.

SOARES, Magda. Letramento: um tema em três gêneros. Belo Horizonte: Autêntica, 1998.

. O que é letramento digital? [S.I.]: Educarede, 2008. Disponível em:

<http://www.educarede.org.br/educa/index.cfm?pg=internet_e_cia.informatica_princi pal\&id_inf_escola=744>. Acesso em: 9 set. 2012.

STALLINGS, William. Arquitetura e organização de computadores: projeto para o desempenho. Trad. Carlos Camarão de Figueiredo e Lucília Camarão de Figueiredo. São Paulo: Prentice Hall, 2002. 


\section{ANEXO A - Notícia 1 - Risco na Rodovia Ilhéus-Itabuna}

RISCO NA RODOVIA ILHÉUS-ITABUNA

16 пm 2012. 10:02 | Autor: scul'mentata

() Derba parece ter esquecido de vez a manutenção e conservação da rodovia Ithéus-ltabuna (BR-415). O mato avançou muito sobre a pista em vários pontos da estrada, aumentando ainda mais os riscos de acidente.

Una das regiões mais perigosas é a curva em frente à estação de tratamento da Embasa, no quilômetro 4 da rodovia. $\mathrm{O}$ avanço foi tão grande que impede at que o motorista que trafega no sentido Ilhéus-Itabuna tenha visào da mào contrária.

Motoristas ainda alertam para o risco de acidentes nas margens da BR-415 no trecho que corta o Banco da Vitória, onde os comerciantes, ignorando os riscos. invadem acostamento e quebra-molas para montar barracas para venda de frutas e pescado. A estes problemas, junta-se outro: as conhecidas crateras ao longo dos 25 quilòmetros da estrada.

Compartille

unw.pimenta.blog.br/2012/05/16/risco-na-rodovia-ilheus-itabuna/ 
IMPRIMIR | ENVIAR | 642 visualizações

Postado em Punemla na Muqueca | Tags: BR-415, Derba. Rodovia Illhéus-Llabuna

23 respostas para "RISCO NA RODOVIA ILHÉUS-ITABUNA"

- wallace sergio disse:

16) IGUTC maio as 10:24 [Citar] [Responder]

O Governador já disse que melhorá a estrada: quando permitimos a privatização dela.

- Marcos Paulo disse:

16. 16UTC main as 10:49 LCitar] [Responder]

Normal. vindo deste governo estadual inoperante.. que esqueceu que o sul da Bahia faz parte do estado tb.

- Humberto disse:

I6 16UTC maio às 10:53 [Citar] [Responder]

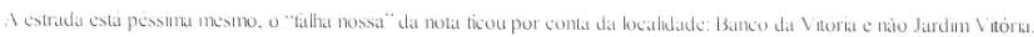

- André Senti disse:

16 16LTC maio às 11:17 \Citar! |Responder!

Nào seria "Banco da Vitória"?

fica aqui o registro.

- To de olho disse

If IfUTC maio as 12:18 [Citar] [Responder]

$\mathrm{Na}$ época do governo que o PT apontava como inoperante a estrada de Itabuna para llhéus era muito bem conservada, não existia nenhum buraco nu trecho

Como o governo Wagareza a estrada mais que duplicou o movimento , foi prometido a duplicaçăo e sequer conseguem tirar o mato que fica na sua margem.

Isto que dá acreditar neste petismo que não consegue sequer fazer uma unica obra na regiào.

Não reclamem. ele foi reeleito com votos do povo de Itabuna

- paulo disse:

se não me engano, hoje o trecho BR415 Itheus/tabuna, encontra-se sob responsabilidade do DENIT E NÃO DO DERBA, fica registrado.

- To de ollho em ve disse:

16 16UTC nkiw is 13:12 [Citar] [Responder]

Deixe de ser mentiroso To de Olho. A estrada sempre foi esburacada e mal sinalizada. Num me venha com peito caido dizendo q é mocinha.

- Maria Ferreira disse

16 16UTC maw is 13,37 [Citar] LResponder]

A estrada é féderal, porem com responsabilidade do estado que recebe dinheiro de Brasilia para conservar. É preciso observar alem da buraqueira, o serviço feito por estes dias estar em péssimo condịcões e em alguns lugares perigoso, como por exemplo na saida de Itabuna para Théus em uma curva antes do condominio jardim das arcacias (aproximadamente 100 metros) estar parecendo um camaleão o carro passa pulando e ainda sem acostamento para os pedestre, UM PERIGO se for com uma certa velocidade pode até cair no rio.

- L'birajara disse:

16) I GUTC maio as 13:45 LCitar] [Responder]

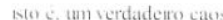

Quem precisa passar pela rodovia Coaraciltajuipe tem sofindo há muito tempo e o governador Wagner continua insensivel, como é insensivel a outros lantos aspectos importantes do Estado.

Até o trecho do semi-anel rodoviário. que tem apenas cerca de $7 \mathrm{Km}$, não recebe a manutenção devida, com destaque para uma velha cratera em frente ao Centro de Recuperaçào Renascer.

Infelizmente contintaremos refëns desse desgoverno Wagner.

- O Ariete disse:

unw. pimenta.blog.br/2012/05/16/risco-na-rodova-ilheus-itabuna/ 


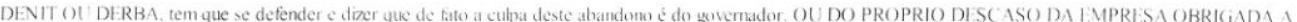
MANUTENCAO O OUTRO SALDOSTTA DA DETONAC AO DO ( NRLISMO EM NOSSA BAHIA QUER DIZER OUE ESTE ABANIONO EDE A(OORA DO)

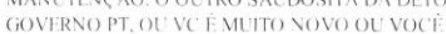

EREALMENTE DOENTE POLTTCAMENTE. O PT ENCONTROL UMA BAHIA SEM EDUCACÁO SEM SAÚdE. SEM SANEAMENTO. SEM

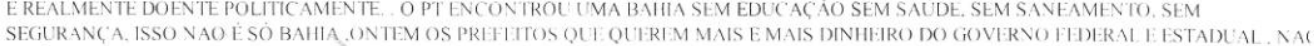
ESTȦO ERRADOS, POREM POR QUE NLNCA COBRARAM DOS GOIFRNANTES ANTES DO PT A REAL. DISTRIBUICȦO DE RENDAS DO PETROLEO

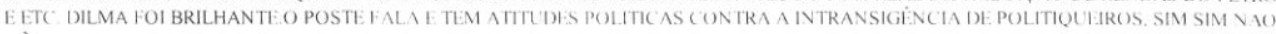
NÀO POR ISSO EU QUERO A MULHER.

Lais dos:

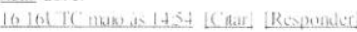

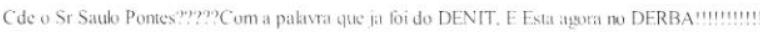

marcos paulo dise

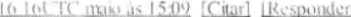

Engano seu meu caro Paulo.. a BR 415 é kedcral mas sob responsabilidade do DERBA.

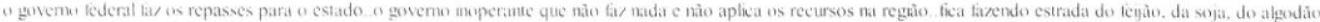

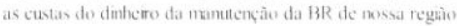

Zumbi disse

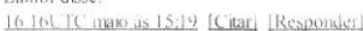

Fstá partcendo un ramall' 'É o governo da Bahia fäzendo mais, para quem unues precisa"

Tudo un da vai mudar tenho fe

Mas uns coisa e cerna.esti esperando acabar para prinatisa

(11).41) io dese

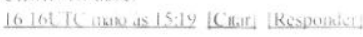

SEJA DFNIT OU DERBA.NȦO IMPORTA. A INCOMPETEXVCIA F. TUTAL.SFJA EL A FFDERAL OU ESTADUAL

Vergonhoso disse

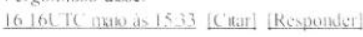

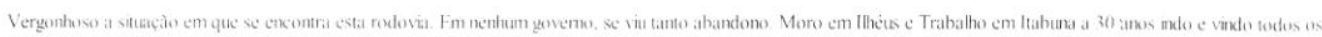

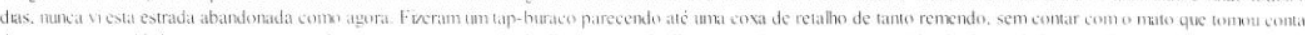

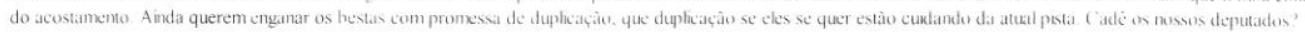

tisboabeto 35 ia hotmail com disse

$16]$ ol IS maic as 15.34 [Citir] [Responder]

Senhor Pincina.

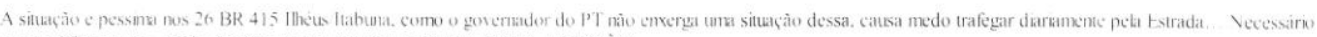
una mobillzaçao no sentido de alerta ao goveriator do VADA P ARA A RF (it io Parabens pela materai.

Zumbi dise

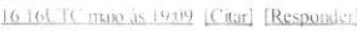

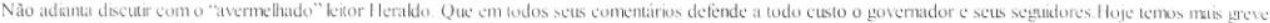

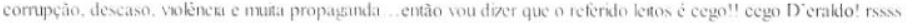

JADER dis:

16) 60 C IC naw is 21.50 Litar, Responder

ATENCAC

No muinno o GERAL.DO SIMỎES VAI ACUSAR O AZEVEDO PEL A PESSIMA CONSERVACȦO DA RODOVIA JORGE AM ADO.

GERALIO SIMÕES \& TURMA DOS PETRALHAS QUL SÃO APAIXONADOS. AMANTES DE TUDO QUE POSSA PREJUDIC ARO SULDA BAIIIA NESTE PERIODO ELEITORAL:

PETRALHIAS ESPERTOS=DONO DE RADIO COMPRADA POR I'M I.AR.ANIA.

PETRALHAS MALINDROS-NO MINIMO VAOINFORMAR NA RADIO D() LARANJA QUE APÓS + ANOS DE JW NO POIDER. I PESSIMA CONSFRVACAO AINDA FFRUTO DA GISTAO DO PALLO SOUTO \& (OMPANHIA

E O PIOR DE TUDO ISSO ĖQUE MUITA GENTE VAI ACREDITAR

PETRALHAS QUE NÄO CONSEGULM IX PLICARO () TRE( HO HERRAI) IS A ITABI NA

PFTRALHAS QUF NÃO CONSEGUEM CONSTRLTR A YOY PONTI DO PONTIL:

PETRALIIAS QUT:FICAM DIZFNDO DE. I MA DU PIICACAODA ROIOUVA JORGIL AMADO. 


\title{
ANEXO B - Notícia 2 - Prefeituras Baianas Descumprem Lei de Acesso à Informação
}

\author{
PREFEITURAS BAIANAS DESCUMPREM LEI DE ACESSO À INFORMACÃO
}

16 mat 2012 . 17:20| Autor: Scu P'imentas

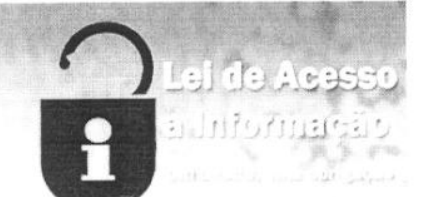

Salvador. Eunápolis, Ithéus, Itabuna, Jequé e Vitoria da Conquista figuram entre as prefeituras baianas que descumprem a Lei de Acesso à Informação em suas páginas na Internet, apesar de manterem Ouvidorias. A lei entrou em vigor nesta quarta, 16. Levantamento

Aša 2011 pela presidente Dilma Roussef. A lei garante acesso à informação aos cidadãos As câmaras municipais também não se adaptaram à lei sancionada em 2011 pela presidente Dilmá Roussef. A lei garante accsso à informaçáo aos cidadáos sobre licitaçùes, contratos. execự

Todos os entes foderativos nas trẻs esferas devem manter as informações acessiveis via Internet ou através de serviços exchusivos para isto. As solicitaçōes dos Todos os entes federativos nas tres de 20 dias. prorrogável por mais dez dias. O descumprimento caracteriza improbidade administrativa dos gestores.

Compartille

AVIAR | 949 visualizações

Postado em Pimenta na Mlugucca 


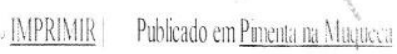

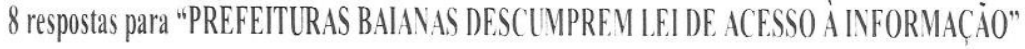

Servin ()inetira disio.

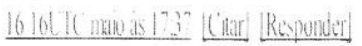

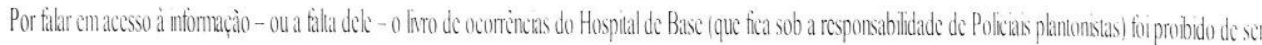
acessado pela imprensa, pelo governo do estado. ...!

Tudo isso depos da repercussào de una repoetagem na televisiò. ....'

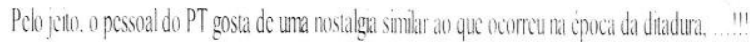

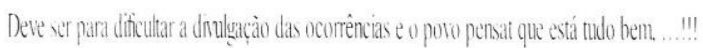

Segưa. pràu. ..!!

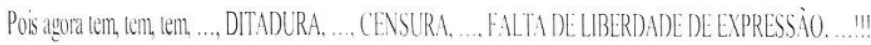

Santo tyostinho disse:

16160TC main as 19.16 (Ciar Respondul]

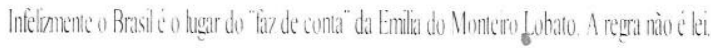

() (III) 11$)$ i() diss:

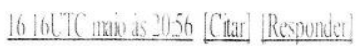

-EDAI. VAI ACONTECER O QUE COM OS GESTORES?

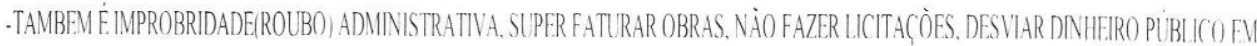

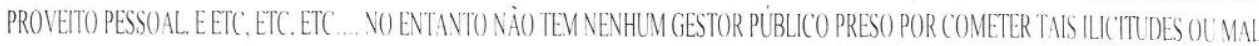
FEITOS, (ONO GOSTA DEDDIZER A PRESIDENTA.

-PORTANTOSRS. ESTAEVAIS LMALEIPARAINGLESUE

Burburu diss:

1717 TC main is 8:02) [Ciar] Responder]

Quem descumpre a lei no brasil é Herói, posis nào da em nada

biguestressudo disse

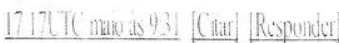

en quiro e novidade!"!!!

Lindentir disse

1712 TC malo as let: [Card Respender]

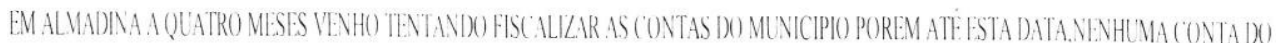

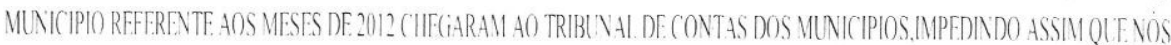

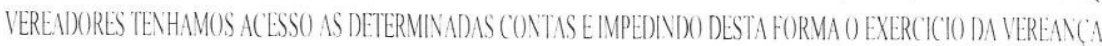
REPUDI0. ASS.VEREADOR JOSFIINDOMAR FERREIRA SANTOS.

(ID)AD): 10 disse

17172TC now is 1351 Litarl Responder

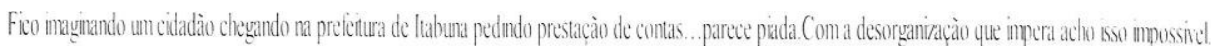




\section{ANEXO C - Notícia 3 - O Golpe (Frustrado) de Coronel Santana}

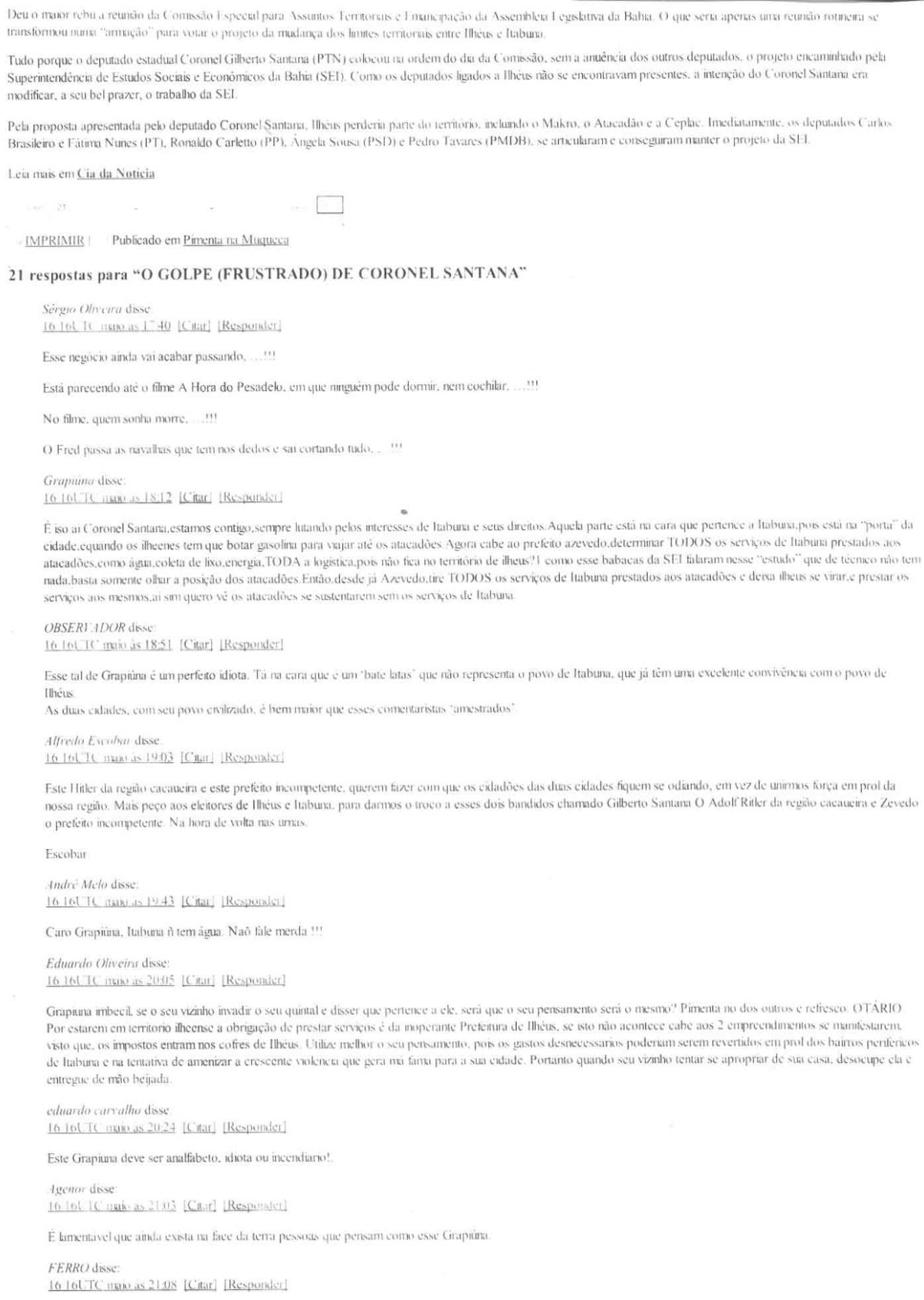

Tudo porque o deputado estadual Coronel Gilberto Santana (PTN) colocuu na orden do da da Comısào. sem a anuència dos outros deputados. o projeto encaminhado pela Superintendència de Estudos Sociais e Económicos da Bahia (SEI). Como os deputados hgados a Ithéts nào se encontravam presentes. a intenção do Coronel Santana cra modificar, a seu bel prazer, o traballho da SEI.

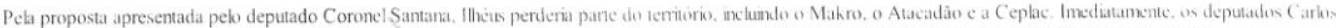
Brasileiro e Fátma Nunes (PT), Ronaldo Carletto (PP), Angela Sotsa (PSD)) e Pedro Tavares (PMI)B), se articularane conseguram nanter o projeto da SH:I.

Leia mais em (ia da Noticia

IMPRIMIIR Publicado em Pimenta na Muquica

21 respostas para "O GOLPE (FRUSTRADO) DE CORONEL SANTANA"

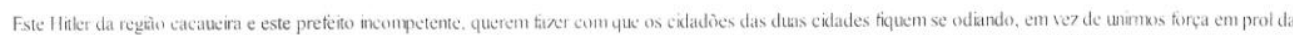
nossa regiảo. Más peço aos eleitores de Illhéus e ltabuna. para darmos o troco a esses dois bandidos chamado Gilberto Santana O Adolf Ritler da regenaio cacaucira e Zevedo o prefeito incompetente. Na hora de volta nas unzas

Escobar

Andre: Mcto disse:

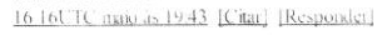

Caro Grapiüra, Itabuna ǹ tem água. Naỏ tile merda !"!

Eduardo (liveira disse:

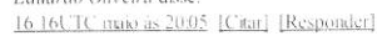

Grapiua imbecil. se o seu vizinho invadir o seu quintal e disser que pertence a ele, sera que o seu pensanknto será o mesme.' Pimenta no dos outros e retiesco. OT ARIO

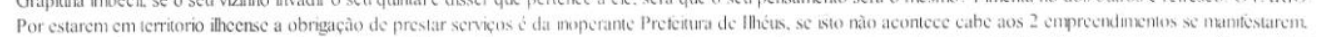

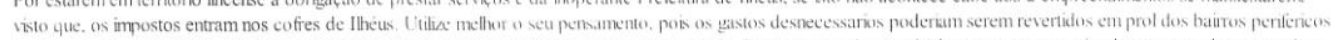

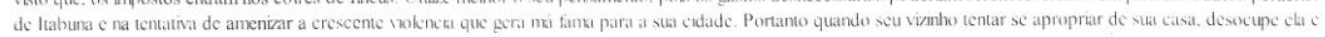
entreque de mào beijadia.

eduardo carvalho disse

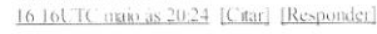

Este Grapiuna deve ser analfabeto, idiota ou incendiaros!

tgenor disse:

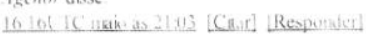

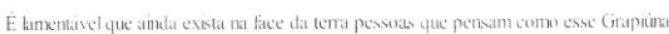

FERRO disse:

16) 160 TC main is 2108 LCitiar] [Respondect 